\title{
Importance of participation rate in sampling of data in population based studies, with special reference to bone mass in Sweden
}

\author{
H Düppe, P Gärdsell, BS Hanson, O Johnell, BE Nilsson
}

\begin{abstract}
Objective - To study the effects of participation rate in sampling on "normative" bone mass data.

Design - This was a comparison between two randomly selected samples from the same population. The participation rates in the two samples were $61.9 \%$ and $83.6 \%$. Measurements were made of bone mass at different skeletal sites and of muscle strength, as well as an assessment of physical activity.

Setting - Malmö, Sweden.

Subjects - There were 230 subjects (117 men, 113 women), aged 21 to 42 years.

Results - Many subjects participated in both studies (163). Those who took part only in the study with the higher participation rate (67) almost invariably had higher values for bone mass density at the sites measured (up to $\mathbf{7 \cdot 6 \%}$ for men) than participants in the study with the lower participation rate. No differences in muscle strength were recorded.

Conclusion - A high degree of compliance is important to achieve a reliable result in determining normal values in population based studies.
\end{abstract}

( $(\mathcal{F}$ Epidemiol Community Health 1996;50:170-173)

In many studies of the effects of different factors (drugs, life style, etc) on bone mass, "normative" data serve as controls, which makes it essential that these values are "true". We have previously focussed on differences between normative data obtained from a randomly selected sample and a sample selected by other means. ${ }^{1}$ In this study we investigated the importance of the participation rate when obtaining "normative" data for bone mass and muscle strength. The study was needed because the participation rate in many studies of bone mineral research is either fairly low or not given at all. We know that even relatively small differences in bone mass are potentially important, for example, a $1 \mathrm{SD}$ reduction in bone mass at its peak is believed to be associated with a 50 to $100 \%$ increased risk of future fracture. ${ }^{23}$ Thus, if participation rates influence the outcome in bone mass studies, this may leas to bias and consequently incorrect conclusions. The influence of different means of selecting participants and reasons for differences in participation rate are also discussed.
The present study is based on two previous studies by independent research groups in which the participants were drawn from the same, well defined population. The participation rates were $61.9 \%$ and $83.6 \%$. Since many participants took part in both of these previous studies, our aim was to see in what way those who only took part in the study with the higher participation rate (declining participation in the other study) differed from those who took part in the study with the lower participation rate $(61.9 \%)$ with regard to bone mass, muscle strength, and the level of physical activity.

\section{Methods}

POPULATION

A study was carried out at the primary health care centre in the suburban community of Kirseberg, Malmö (11 000 residents) between 1990 and 1995. This population was studied by two university departments independently - the Department of Community Health Sciences and the Department of Orthopaedics, both in Malmö

For both studies, identical lists of inhabitants of Kirseberg were taken from city files and used for participant selection.

Kirseberg health project

Between 1990 and 1995 the Department of Community Health Sciences invited all residents aged 20 to 45 (about 5000 individuals) to participate in a health examination which was free of charge and without any inducement offer and was administered by a nurse at the primary health care centre. Written invitations were sent out and those who did not respond were followed up by telephone. The purpose of this health examination was not only scientific, it was also an opportunity for residents in Kirseberg to have a medical check up (blood pressure, cholesterol level, alcohol, and smoking habits, etc).$^{4}$ In the present study we have included the first part of this health examination. From 1990-91, 839 men and women aged 20 to 41 were invited to take part, and 519 participated $(61.9 \%)$.

\section{Orthopaedic study}

At the Department of Orthopaedics we have been studying subjects from the same population to serve as "normative" data for sub- 
sequent research and to determine at which age bone mass peaks in this population based sample. We were also trying to identify the determinants of peak bone mass such as muscle strength.

Peak bone mass is believed to be one of the major factors that contributes to bone quality later in life, since a high peak bone mass seems to reduce future fracture risk. ${ }^{235}$ The development of bone mass towards its peak, is governed mainly by heriditary factors. ${ }^{6-8} \mathrm{Nu}-$ tritional factors, especially calcium intake, may have an influence, ${ }^{9-11}$ as do some lifestyle factors such as smoking, alcohol consumption, and the level of physical activity. ${ }^{12-15}$

Altogether 275 men and women aged 21 to 42 were randomly selected and invited to participate. The letter of invitation stated that participants would be informed about their muscle strength and given an opportunity to compare their results with other participants and local athletes. In addition, participants would be given two cinema tickets as an inducement. Non-respondants were contacted by telephone. Of the 275 invited, 230 participated $(83 \cdot 6 \%)$.

\section{Methods}

When comparing the databases of the two studies, we found that 163 ( 77 men, 86 women) of the 230 participants in the orthopaedic study had also participated in Department of Community Health Sciences Study. Thus, 67 (40 men, 27 women) participated in the orthopaedic study only.

Comparisons were made between two groups. Group A, which comprised those participating in both studies described above (The Kirseberg health project and The orthopaedic study), had a participation rate of $61.9 \%$. Group B comprised those who took part only in the orthopaedic study (who were invited but did not participate in the Kirseberg Health Project) and in effect increased the participation rate to $83.6 \%$ (figure).
MEASUREMENT OF BONE MASS DENSITY (BMD) BMD $\left(\mathrm{g} / \mathrm{cm}^{2}\right)$ was measured at the spine (LIIIV), hip (neck, trochanter, and Ward's triangle) and for the total body (dual energy $x$ ray absorptiometry (DEXA) method), as well as the forearm (single photon absorptiometry (SPA) method), ${ }^{16}$ where both distal (SPA 1 mostly trabecular bone) and proximal (SPA 6 - mainly cortical bone) measurements were made.

\section{MEASUREMENT OF MUSCLE STRENGTH}

Measurements were made at the leg (mainly the quadriceps muscles), using a Biodex equipment (Smith \& Nephew). PT 60 (peak torque, angular velocity $60 \%$ second) and TW 60 (total work, angular velocity $60 \%$ second) were assessed as determinants of muscle strength.

\section{PHYSICAL ACTIVITY}

A questionnaire was used to assess physical activity levels at work and during leisure. Participants were asked to state which of the given alternatives corresponded best to their own level of activity at work during the past year. Physical activity during leisure was assessed in a similar way but here a score was created in order to take seasonal variations into account (Appendix).

\section{STATISTICAL ANALYSIS}

Variables between groups A and B were compared by Student's $t$ test. For non-parametric comparisons the Mann-Whitney U test was used. Statistical significance was set at the 0.05 level of probability. Statistica (1984-94 StatSoft, Inc) software was used for statistical analysis of data on a Macintosh microcomputer (Apple Computer Inc).

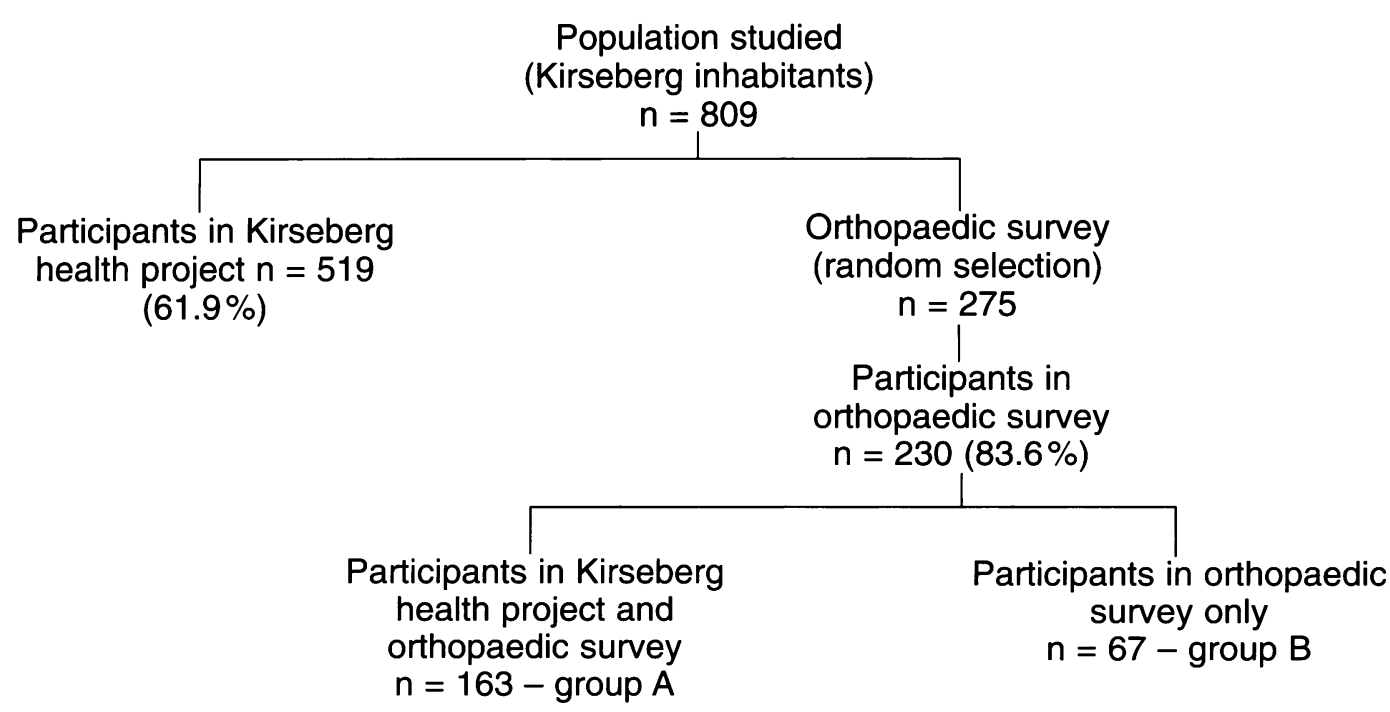


Table 1 Age, weight, and height of participants in both studies (group $A$ ) and in the orthopaedic study only (group B).

\begin{tabular}{lcc}
\hline & Group $A$ & Group B \\
\hline Women & & \\
No & 86 & 27 \\
Age, mean (SD) & $31 \cdot 8(7 \cdot 0)$ & $64 \cdot 3(7 \cdot 5)$ \\
Weight, mean (SD) (kg) & $65 \cdot 2(12 \cdot 5)$ & $166 \cdot 1(6 \cdot 2)$ \\
Height, mean (SD) (cm) & $167 \cdot 2(6 \cdot 6)$ & \\
Men & & 40 \\
No & 77 & $30 \cdot 1(6 \cdot 8)$ \\
Age, mean (SD) & $31.5(7 \cdot 3)$ & $78 \cdot 2(12 \cdot 8)$ \\
Weight, mean (SD) (kg) & $76.5(10 \cdot 2)$ & $179 \cdot 6(5 \cdot 8)$ \\
Height, mean (SD) (cm) & $180 \cdot 4(7 \cdot 1)$ &
\end{tabular}

\section{Results}

Men and women participating in the orthopaedic study only (group B) were younger than those participating in both studies (group A) but the difference was not statistically significant. Furthermore, there was a sex difference between the two groups. No statistically significant differences in height or weight between the groups were found (table 1).

\section{BMD MEASUREMENTS}

For those participating in the orthopaedic study only (group B), the BMD was higher in the hip for both men and women $(5 \cdot 0-7 \cdot 6 \%)$ compared with values in those participating in both studies (group A). These differences were statistically significant for men for the femoral neck $(p=0.017)$ and for the trochanter $(p=0.020)$. Similar, although smaller, differences were seen at other sites measured, with the exception of the distal forearm site in women (table 2).

\section{MEASUREMENT OF MUSCLE STRENGTH}

No significant difference in quadriceps muscle strength could be found between the two groups for either men or for women (table 3).

PHYSICAL ACTIVITY

Our questionnaire, which had a scoring system for levels of physical activity, showed a trend.
Those who took part only in the orthopaedic study (group B), had more physically demanding work than those who took part in both studies (group A), but this trend was not statistically significant at the 0.05 level of probability (table 3 ). When studying the degree of physical activity in leisure activities, the same trend was also found, with a higher degree of activity for group $B$.

\section{Discussion}

In this study of the effect of an increase in the participation rate in sampling bone mass data, we found a higher BMD at many sites for men and women in those who were taking part only in the study with the higher participation rate (group B). Thus, this group of participants, "lost" to the study with the lower participation rate, were different. This brings us to the conclusion that the participation rate can influence the outcome in a study of, as in this case, "normative" bone mass data. This is important, since there are studies in the field of bone mineral research in which participation rates are comparatively low or not mentioned.

Differences in BMD levels were most obvious at the hip sites $(5 \cdot 0-7 \cdot 6 \%)$, and were significant for men in the neck and the trochanter. This is maybe explained by differences in levels of physical activity. Although, not statistically significant in this sample size, and perhaps difficult to detect in a questionnaire of the type used here, there was a trend that subjects who took part only in the orthopaedic study (group B) were more physically active than the others (group A). In a previous study by the authors, (Düppe et al, in preparation) we found that those who are more physically active, at work as well as in their spare time, tended to have a higher BMD than those who were less physically active. This was most obvious in men and was significant at the hip sites. Therefore, a possible explanation for the differences in BMD between the two groups

Table 2 Bone mineral density (BMD) at measured sites for participants in both studies (group $A$ - participation rate $61.9 \%$ ), and in the orthopaedic study only (group $B$-participation rate $83.6 \%$ ).

\begin{tabular}{|c|c|c|c|c|c|c|c|c|}
\hline & \multicolumn{3}{|c|}{ Group $A$} & \multicolumn{3}{|c|}{ Group B } & \multirow[t]{2}{*}{$p$ value } & \multirow{2}{*}{$\begin{array}{l}B M D \text { difference, } \\
\text { group } A-B(\%)\end{array}$} \\
\hline & No & Mean & $(S D)$ & No & Mean & $(S D)$ & & \\
\hline \multicolumn{9}{|l|}{ Women } \\
\hline \multicolumn{9}{|l|}{ BMD, SPA $\left(\mathrm{mg} / \mathrm{cm}^{2}\right)$} \\
\hline $1 \mathrm{~cm}$ (mostly trabecular bone) & 86 & 318 & (59) & 27 & 318 & $(50)$ & 0.992 & $(0)$ \\
\hline $\begin{array}{l}6 \mathrm{~cm} \text { (mainly cortical bone) } \\
\text { BMD, DEXA }\left(\mathrm{mg} / \mathrm{cm}^{2}\right)\end{array}$ & 85 & 538 & (52) & 27 & 524 & (59) & $0 \cdot 238$ & $(-2 \cdot 7)$ \\
\hline Spine & 86 & $1 \cdot 17$ & $(0 \cdot 13)$ & 27 & $1 \cdot 19$ & $(0 \cdot 12)$ & BMD, DEXA $\left(\mathrm{mg} / \mathrm{cm}^{2}\right):$ & $(1 \cdot 7)$ \\
\hline Total body & 86 & $1 \cdot 15$ & $(0 \cdot 07)$ & 27 & $1 \cdot 17$ & $(0.07)$ & 0.207 & $\begin{array}{l}(1 \cdot 7) \\
(1 \cdot 7)\end{array}$ \\
\hline \multicolumn{9}{|l|}{ Hip: } \\
\hline Femoral neck & 85 & $1 \cdot 00$ & $(0 \cdot 13)$ & 27 & 1.05 & $(0 \cdot 13)$ & 0.085 & $(5 \cdot 0)$ \\
\hline Ward's triangle & 85 & 0.94 & $(0 \cdot 16)$ & 27 & 1.00 & $(0 \cdot 14)$ & 0.083 & $(6 \cdot 4)$ \\
\hline Trochanter & 85 & $0 \cdot 83$ & $(0 \cdot 12)$ & 27 & $0 \cdot 88$ & $(0 \cdot 13)$ & $0 \cdot 057$ & $(6 \cdot 0)$ \\
\hline \multicolumn{9}{|l|}{ Men } \\
\hline \multicolumn{9}{|l|}{$\mathrm{BMD}, \mathrm{SPA}\left(\mathrm{mg} / \mathrm{cm}^{2}\right)$} \\
\hline $1 \mathrm{~cm}$ (mostly trabecular bone) & 74 & 416 & (61) & 40 & 419 & $(60)$ & 0.751 & $(0 \cdot 7)$ \\
\hline $6 \mathrm{~cm}$ (mainly cortical bone) & 76 & 617 & (56) & 39 & 630 & (68) & $0 \cdot 270$ & $(2 \cdot 1)$ \\
\hline $\mathrm{BMD}, \mathrm{DEXA}\left(\mathrm{mg} / \mathrm{cm}^{2}\right):$ & 76 & $1 \cdot 13$ & $(0 \cdot 10)$ & 40 & $1 \cdot 15$ & $(0 \cdot 13)$ & 0.326 & $(1 \cdot 8)$ \\
\hline Total body & 76 & $1 \cdot 19$ & $(0.08)$ & 40 & $1 \cdot 22$ & $(0 \cdot 08)$ & 0.086 & $(2 \cdot 5)$ \\
\hline \multicolumn{9}{|l|}{ Hip: } \\
\hline Femoral neck & 76 & 1.01 & $(0 \cdot 15)$ & 40 & 1.07 & $(0 \cdot 15)$ & 0.017 & $(5 \cdot 9)$ \\
\hline Ward's triangle & 76 & 0.92 & $(0 \cdot 18)$ & 40 & 0.99 & $(0 \cdot 17)$ & 0.055 & $(7 \cdot 6)$ \\
\hline Trochanter & 76 & $0 \cdot 89$ & $(0 \cdot 14)$ & 40 & 0.95 & $(0 \cdot 14)$ & 0.020 & $(6 \cdot 7)$ \\
\hline
\end{tabular}

SPA $=$ Single photon absorptiometry; DEXA $=$ dual $x$ ray absorptiometry. 
Table 3 Quadriceps muscle strength (Biodex) and physical activity scores for both groups

\begin{tabular}{|c|c|c|c|}
\hline & Group $A$ & Group B & \\
\hline \multicolumn{4}{|l|}{ Women } \\
\hline \multicolumn{4}{|l|}{ Muscle strength: } \\
\hline No. & 81 & 26 & \\
\hline Peak torque, mean (SD) & $144(30)$ & $140(29)$ & $p=0.595$ \\
\hline Total work, mean (SD) & $721(193)$ & $736(170)$ & $\mathrm{p}=0.726$ \\
\hline \multicolumn{4}{|l|}{ Physical activity: } \\
\hline No. & 86 & 27 & \\
\hline At work (score) mean (SD) & $(3 \cdot 1)$ & $(3 \cdot 2)$ & $p=0.098$ \\
\hline During leisure (score) mean (SD) & $(4 \cdot 5)$ & $(4 \cdot 8)$ & $\mathrm{p}=0 \cdot 100$ \\
\hline \multicolumn{4}{|l|}{ Men } \\
\hline \multicolumn{4}{|l|}{ Muscle strength: } \\
\hline No. & 72 & 39 & \\
\hline Peak torque, mean (SD) & $229(43)$ & $232(40)$ & $p=0.711$ \\
\hline Total work, mean (SD) & $1135(260)$ & $1103(231)$ & $p=0.523$ \\
\hline \multicolumn{4}{|l|}{$\begin{array}{l}\text { Physical activity: } \\
\text { P }\end{array}$} \\
\hline No. & 77 & 40 & \\
\hline At work (score) mean (SD) & $(3 \cdot 2)$ & $(3 \cdot 5)$ & $\mathrm{p}=0.115$ \\
\hline During leisure (score) mean (SD) & $(5 \cdot 0)$ & $(5 \cdot 5)$ & $\mathrm{p}=0.359$ \\
\hline
\end{tabular}

in the present study may be their different degrees of physical activity.

Why were there differences in the participation rates and why were those "lost" to the study with the lower participation rate more active? The differences in participation rate are probably partly explained by the fact that two cinema tickets were offered as an inducement to those taking part in the study with the higher participation rate. Another explanation for this, and for the different levels of activity between the groups, might be the design of the letter of invitation. The invitations were similar in that both were invitations to a type of health examination, but in the invitation to the group with the higher participation rate it was also stated that subjects were taking part in a research project and would be informed about their muscle strength and be given the opportunity to compare their results with other participants and local athletes. It is probably fair to assume that men and women aged 2142 , like the participants in this study, are more interested in being informed about their muscle strength than, for example, their cholesterol level, and this may partly explain differences in participation rates. Furthermore, an invitation to test muscle strength will probably appeal more to the physically active, especially men, who want to confirm that they are fit, and this could explain differences in levels of physical activity between the groups. There was no statistically significant difference in muscle strength between the two groups, but we have seen in previous studies which we have undertaken, that quadriceps muscle strength (measured by Biodex) does not seem to be a reliable indicator of the level of physical activity at work or at leisure.

The common finding from voluntary health examinations of this type is that there is a difference in participation rates between different social groups. Studies have shown that there is a lower rate in manual workers, subjects living alone, immigrants, and those with a low level of education. ${ }^{17-19}$ This does not seem to be the case, however, in the study by the Department of Community Health Sciences (group A), where a comparison was made between participants and non-participants with regard to social class, level of education, and economic status. No significant differences were found. ${ }^{20}$ Thus, it is improbable that differences between those participating in study $\mathrm{A}$ and study $\mathrm{B}$ can be explained by differences in socioeconomic factors.

A high degree of "compliance" is of importance in order to get a reliable result when conducting a clinical trial (H Düppe et al personal communication) such as a drug trial. The same seems to be the case when conducting a population based study in order to obtain bone mass data, as in this study, emphasising the importance of high participation rates when sampling data in bone mineral research, a fact that is perhaps not always acknowledged.

1 Düppe H, Gärdsell P, Johnell O, Nilsson BE. Bone minera content in women: Trends of change. Osteoporosis International 1992;2:262-5.

2 Hui SL, Slemenda CW, Johnston CC Jr. Baseline measurement of bone mass predicts fracture in white women. Ann Intern Med 1989;111:355-61.

3 Cummings SR, Black DM, Nevitt MC et al. Appendicular bone density and age predict hip fractures in women. JAMA 1990;263:665-8.

4 Hanson BS, Larsson S. Early experiences from the Kirseberg Public Health Project in Malmö, Sweden. An alcohol prevention campaign. Health Promotion International 1991; 6:111-19.

5 Wasnich RD. Fracture prediction with bone mass measurements. In: Genant HK, ed. Osteoporosis. San Francisco: Radiology Research and Education Foundation, 1987: 95-101.

6 Smith DM, Nance WE, Kang K, Christian JC, Johnston $\mathrm{CC} \mathrm{Jr}$. Genetic factors in determining bone mass in adults: a twin study. $\mathcal{F}$ Clin Invest $1973 ; 52: 2800-8$

7 Pocock NA, Eisman JA, Hopper JL, Yeates MG, Sambrook PN, Ebert S. Genetic determinants of bone mass in adults: a twin study. $\mathcal{F}$ Clin Invest 1987;4:737-41.

8 Seeman E, Hopper JL, Bach LA et al. Reduced bone mass in daughters of women with osteoporosis. $N \mathrm{Engl} \mathrm{f} \mathrm{Med}$ in daughters of wom

9 Sandler RB, Slemenda CW, La Porte RE et al. Postmenopausal bone density and milk consumption in childhood and adolescence. Am $\mathcal{F}$ Clin Nutr 1985;40:270-4.

10 Halioua L, Anderson J. Lifetime calcium intake and physical activity habits: independent and combined effects on the radial bone of healthy premenopausal caucasian women Am $\mathcal{F}$ Clin Nutr 1989;49:534-41.

11 Matkovik V, Fontana D, Tominac, Goel P, Chestnut CH III. Factors that influence peak bone mass formation: study of calcium balance and the inheritance of bone mass in adolescent females. Am $\mathcal{F}$ Clin Nutr 1990;52:878-88.

12 Slemenda CW, Miller JZ, Hui SL et al. Role of physical activity in the development of skeletal mass in children. $f$ activity in the development of skel
Bone Miner Res 1991;6:1227-33.

13 Nilsson BE, Westlin NE. Bone density in athletes. Clin Orthop 1971;77:177-82.

14 Huddlestone AL, Rockwell D, Kulund DN. Bone mass in lifetime tennis athletes. $\mathscr{F} A M A$ 1970;224:1107-9.

15 Snow-Harter C, Bouxseim M, Lewis B et al. Muscle strength as a predictor of bone mineral density in young women. f Bone Min Res 1990;5:589-95.

16 Nauclér LOW, Nilsson BE, Westlin NE. An apparatus for gamma absorptiometry of bone: technical data. Opuscula Medico-Technica Lundensia $1974 ; 12: 1$.

17 Pirie PL, Elias WS, Wackman DB et al. Characteristics of participants and non-participants in a community cardiovascular disease risk factor screening: The Minnesota heart health Program. Am f Prev Med 1986;2:20-25.

18 Pill R, French J, Harding K, Stott N. Invitation to attend a health check in a general practice setting: comparisons of attenders and non-attenders. $\mathcal{F} R$ College Gen Pract of attenders

19 Janzon J, Steen B, Hanson BS, Isaacson S-O, Lindell S-E. Factors influencing participation in health surveys. Results
anzon from prospective population study "men born in 1914" in Malmö, Sweden. $\mathcal{F}$ Epidemiol Community Health 1986 40:174-77.

20 Friedman LM, Furberg CD, DeMets DL. Fundamentals of clinical trials. Littletown, MA: Wright PSG, 1984. 